\title{
Internucleosomal DNA fragmentation is not obligatory for castration induced rat ventral prostate cell apoptosis in vivo
}

\author{
Xuejun Zhang ${ }^{1}$, Antonio J. DeCarli' and Ralph Buttyan ${ }^{1,2}$ \\ 1 The Department of Urology, The College of Physicians and Surgeons of \\ Columbia University, 630 W. 168th Street, New York, NY 10032 USA. tel: 212 \\ 305-1574; fax: 212-305-1564 \\ 2 corresponding author: The Department of Urology, The College of Physicians \\ and Surgeons of Columbia University, 630 W. 168th Street, New York, NY \\ 10032 USA. tel: 212-305-1574; fax: 212-305-1564
}

Received 22.5.96; revised 28.8.96; accepted 18.10.96

Edited by C.J. Thiele

\begin{abstract}
Castrated male rats were treated with the reversible $S_{1}$-phase cell cycle blocking drug, mimosine, and the effects of this drug on prostate cell apoptosis was characterized. At a single dose of mimosine (25 mg/kg/day), we found that the internucleosomal DNA fragmentation associated with apoptosis was partially suppressed in the rat ventral prostate at all early time points $(24,48$ and $72 \mathrm{~h}$ ) analyzed post-castration. This suppression was dose-dependent, and treatment with mimosine up to $150 \mathrm{mg} / \mathrm{kg} /$ day was sufficient to reduce the internucleosomal DNA fragmentation in the prostate by $90 \%$ at $72 \mathrm{~h}$ post-castration. Intriguingly, this drug did not suppress the induction of mRNAs for several apoptosis-associated gene products in the ventral prostate gland (bcl-2, p53, TGF- $\beta$ and SGP-2/clusterin). Moreover, this treatment did not suppress the histological appearance of apoptotic bodies in the ventral prostate detectable by fast green staining of thin sections of tissue. The apoptotic bodies present in mimosinetreated regressing ventral prostate tissues, however, were refractory to labeling by the in situ gap labeling method, further demonstrating lack of nuclear DNA fragmentation in the condensed nuclei of apoptotic cells. In summary, the cell cycle-blocking drug mimosine does not appear to affect the rate of apoptosis in the regressing rat ventral prostate gland. However, this drug was capable of suppressing the nuclear DNA fragmentation associated with androgen-regulated prostate cell apoptosis. These results support the concept that nuclear DNA fragmentation is not obligatory for apoptosis. Additionally, they imply that cell cycle movement from the $G_{1} / S$-phase boundary might be important for the terminal DNA degradation associated with androgen-regulated prostate cell apoptosis.
\end{abstract}

Keywords: prostate gland; androgens; apoptosis; cell cycle; mimosine; DNA fragmentation

Abbreviations: ISGL, in situ gap labeling; TCA, trichloroacetic acid; EDTA, ethylenediamine tetraacetic acid; ip, intraperitoneal

\section{Introduction}

The ventral prostate gland of the rat has provided an ideal in vivo model system to study the cellular, biochemical and molecular events associated with apoptosis (Colombel and Buttyan, 1995). In a mature male, this tissue will lose up to $85 \%$ of its cellular population within the 2 weeks following castration (Berges et al, 1993). The secretory epithelial cells of this organ are highly dependent on testosterone and castration initiates the onset of their apoptosis in a very predictable manner (Sanford et al, 1984). Like many other in vitro cell models of apoptosis, the androgen-deprived prostate epithelial cell undergoes a series of morphological and biochemical changes exemplified by cytoplasmic blabbing, nuclear condensation and pyknosis in conjunction with internucleosomal degradation of the nuclear DNA (Colombel and Buttyan, 1995). As with other apoptotic systems, the nuclear DNA degradation is easily visualized by the detection of a prototypic DNA 'ladder' following agarose gel electrophoresis of DNA extracted from a regressing rat prostate gland. The DNA fragmentation can also be recognized in situ in fixed regressing rat prostate tissues by any of a number of immunohistochemical staining techniques that detect the enzymatic incorporation of chemically-modified nucleotides into fragmented DNA by exogenous DNA polymerase or terminal transferase.

Early experiments indicated that this in vivo system of apoptosis is, at least partially, dependent on RNA and protein synthesis (Lee, 1981). More recently, a large number of studies have demonstrated that several specific mRNAs and proteins are induced in the apoptotic prostate cell (Colombel and Buttyan, 1995). Since some of these apoptosis-induced gene products are linked to cell cycle progression (for examples c-myc, PCNA, p53), it has been proposed that there is some cell cycle movement in prostate epithelial cells associated with androgen deprivation that is important for the onset of apoptosis (Buttyan et al, 1988; Colombel et al, 1992; Zhang et al, 1994). Specifically, since many of these same gene products are induced prior to or at the $G_{1} / S$ boundary, the suggestion has been put forth that androgen-dependent prostate cell apoptosis occurs in conjunction with cell transition to the early S-phase of the cell cycle (Buttyan, 1991). This is a controversial hypothesis (Colombel et al, 1992) and one that has been relatively difficult to test because androgendependent apoptosis is only known to occur in certain tissues in vivo. One test of this hypothesis would be to treat castrated male rats with an agent that is known to inhibit cell cycle progression, especially in the early stage, and determine the effects of such treatment on prostate cell apoptosis.

For this reason, we chose to test the effects of a novel drug, mimosine $[\beta-\mathrm{N}$ (3-hydroxy-4-pyridone) $\alpha$-amino propionic acid] on the characteristic parameters of 
apoptosis in the regressing ventral prostate glands of male rats. This drug is a non-proteinogenic amino acid naturally occurring in the legume genera Mimosa and Leucaena (Thompson et al, 1969). We felt it was an appropriate agent for these experiments because several in vitro studies have established that it reversibly blocks the cell cycle at or near the $G_{1} / S$ boundary (Watson et al, 1991). Secondly, unlike other cell-cycle blocking agents, this drug is not known to be extensively metabolized by the liver or other tissues. Finally, mimosine has already been shown effective in suppressing cell proliferation, in vivo, in a dose-dependent manner when administered to rodents (Crounse et al, 1962). The results presented here demonstrate that this agent, while not blocking the apoptotic process in the androgen-deprived rat prostate gland, does affect at least one important phenotypic characteristic of the apoptotic cell, namely, the prototypic internucleosomal DNA fragmentation that is commonly associated with apoptosis. Since it is now better understood that this drug blocks cells at the beginning of the S-phase (Hughes and Cook, 1996), this suggsts that DNA metabolic activity within the S-phase might be important for the DNA fragmentation associated with this type of apoptosis.

\section{Results and Discussion}

\section{Internucleosomal DNA fragmentation is suppressed in the regressing rat prostate gland by mimosine treatment}

One of the most characteristic markers for apoptosis is a prototypic pattern of nuclear DNA degradation that results in the generation of nuclear DNA fragments in multiples of approximately $180 \mathrm{bp}$ (Kyprianou and Isaacs, 1988). This degradation pattern is often attributed to the activation of endogenous nucleases associated with the onset of apoptosis that digest DNA primarily in the internucleosomal regions. When DNA from tissues containing apoptotic cells (such as the regressing rat ventral prostate gland) is electrophoresed on an agarose gel, the DNA fragments migrate in a characteristic pattern described as a ladder because of the regular series of bands generated by DNA fragments in multiples of the $180 \mathrm{bp}$ motif. This DNA ladder is readily demonstrated in Figure 1, where DNA was extracted from rat ventral prostate specimens obtained at 1,2 and 3 days after castration, electrophoresed on a $1.5 \%$ agarose gel and stained with ethidium bromide. In DNA extracted from prostate tissues obtained at comparable times from castrated rats that were treated with mimosine (oral supplementation $25 \mathrm{mg} / \mathrm{kg} /$ day), however, the intensity of the DNA ladder is decreased and densitometric evaluation of the film negative taken from this gel suggest a $30-50 \%$ reduction in DNA fragments at the three different time points with mimosine treatment. An additional dose-escalation experiment involving intraperitoneal administration of mimosine established that the suppression of internucleosomal DNA fragmentation by this drug was dose dependent. Figure 2 shows an ethidium bromide-stained agarose gel of DNAs extracted from ventral prostate tissues obtained from 3 day castrated rats that had

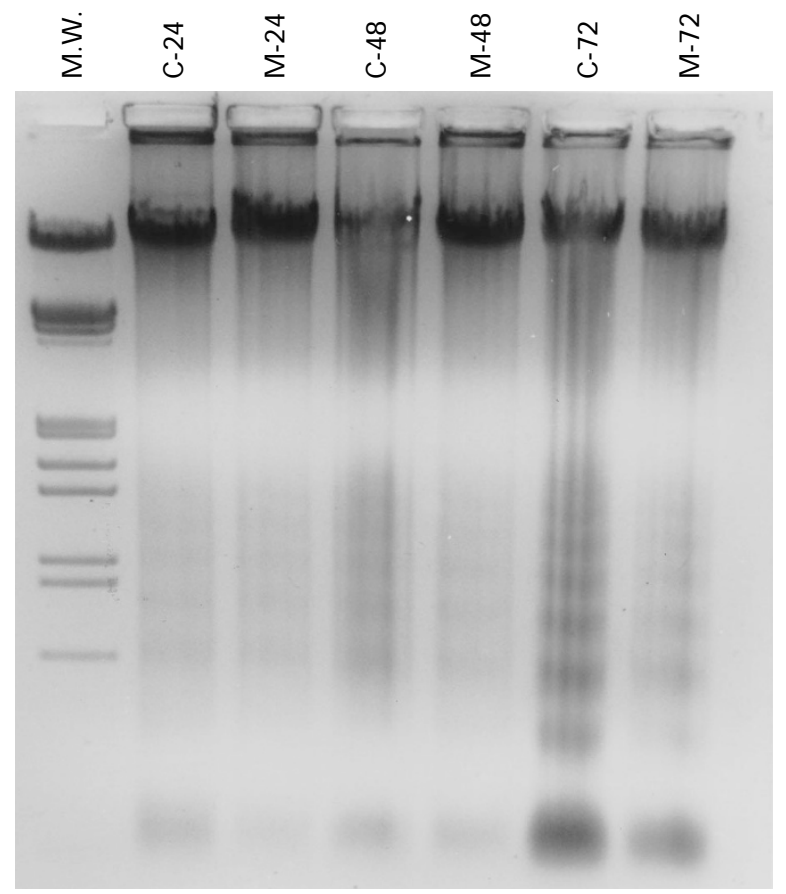

Figure 1 Mimosine treatment (25 mg/day, orally) suppresses apoptotic DNA fragmentation in the regressing ventral prostate glands of castrated rats. Electrophoretic analysis of DNA extracted from mimosine-treated (M-) and -untreated (C-) rat ventral prostate glands at various times after castration (24, 48 and $72 \mathrm{~h}$, as indicated). Aliquots of DNAs (10 ugs) extracted from tissues, as indicated, were co-electrophoresed on a $1.5 \%$ agarose gel. The gel was stained with ethidium bromide and photographed directly under ultraviolet light. Compared to untreated rats, mimosine treatment suppressed the appearance of the DNA fragmentation ladder at all time points after castration.

been treated with mimosine in sequentially increasing doses. At the highest treatment dose (150 mg/kg/day, i.p.), mimosine effectively suppressed the appearance of DNA fragments by $90 \%$ as estimated by densitometric analysis of the film negative taken on this gel. If this prototypical DNA fragmentation was used as the only criterion identifying apoptosis in regressing prostate tissue, these results would suggest that mimosine treatment was highly effective in suppressing androgen-dependent apoptosis.

\section{Mimosine does not inhibit protein syntheses in the regressing rat prostate gland}

Previous studies have determined that regression of the rat ventral prostate gland can be suppressed by protein synthesis inhibitors (Lee, 1981). Although the mechanism of action of mimosine has been reported to be more related to its iron-chelating effects (Dai et al, 1994), this substance is an $\alpha$-amino acid analogue. Therefore, we wanted to determine whether the suppression of nuclear DNA fragmentation in the regressing prostate gland by this drug might be due to its effects on protein synthesis. To ensure that mimosine treatment is not specifically inhibiting protein synthesis in regressing rat prostate gland, we measured the in vivo incorporation of $\left[{ }^{35} \mathrm{~S}\right]-$ methionine into proteins extracted from the regressing glands of mimosine-treated 
and -untreated rats. One group of rats received $150 \mathrm{mg} / \mathrm{kg} /$ day of mimosine for $48 \mathrm{~h}$ subsequent to castration. Control rats without mimosine were simply castrated and subsequently maintained under normal conditions for $48 \mathrm{~h}$. Both groups then received a bolus of $\left[{ }^{35} \mathrm{~S}\right]$-methionine administered intravenously. Two hours later, all rats were sacrificed and the regressing ventral prostates were removed and processed to determine the extent of incorporation of the radiolabeled methionine into TCA-precipitable proteins. We found that there was no difference in the amount of radiolabeled methionine incorporation in the regessing prostate glands between these two groups of rats (mimosine-treated $3.01 \pm 0.30 \times 10^{3} \mathrm{cpm} / \mathrm{mg}$ tissue vs $2.4 \pm 0.61 \times 10^{3} \mathrm{cpm} / \mathrm{mg}$ tissue in the untreated group) ( $n=6$ for each group, no significant difference between these groups). Our results indicated that mimosine treatment did not significantly affect $\left[{ }^{35} \mathrm{~S}\right]$-methionine incorporation by the regressing rat prostate gland. Thus, the suppression of internucleosomal DNA fragmentation in the regressing prostate glands of mimosine-treated rats was not a generalized result of a suppression of protein synthesis by this drug.

\section{Effect of mimosine on the apoptosis-associated gene expression in the regressing rat ventral prostate gland}

To determine whether mimosine altered other biochemical characteristics associated with apoptosis in the regressing ventral prostate gland, we analyzed RNAs extracted from these tissues for the expression of gene products that were previously shown to be induced after castration. RNase protection assays were used to evaluate the relative amounts of TGF- $\beta, \mathrm{p} 53, \mathrm{bcl}-2$ and SGP-2/clusterin mRNAs in control rat ventral prostate gland and in regressing ventral prostate glands obtained at $72 \mathrm{~h}$ post-castration, with or without mimosine treatment. As was previously reported (Zhang et al, 1994; Kyprianou and Issacs, 1989; Buttyan et al, 1989; McDonnell et al, 1992), all of these mRNAs are significantly elevated in the post-castrated ventral prostate when compared to the amount expressed in control prostate tissue (Figure 3). Mimosine treatment did not affect the apparent degree of induction for any of these mRNA species. The apparent lack of effect of mimosine on the induced expression of these gene products is in contrast to the results obtained in the DNA fragmentation experiments and suggests that other characteristic parameters of apoptosis are unaltered by mimosine treatment.

\section{Mimosine treatment inhibits the detection of apoptotic bodies by ISGL}

In situ gap labeling (ISGL) is one version of a familiar combined enzymatic/immunohistochemical technique that enables the detection of cell nuclei with fragmented DNA in thin sections of fixed tissues (Meyaard et al, 1992; Wijsman
A
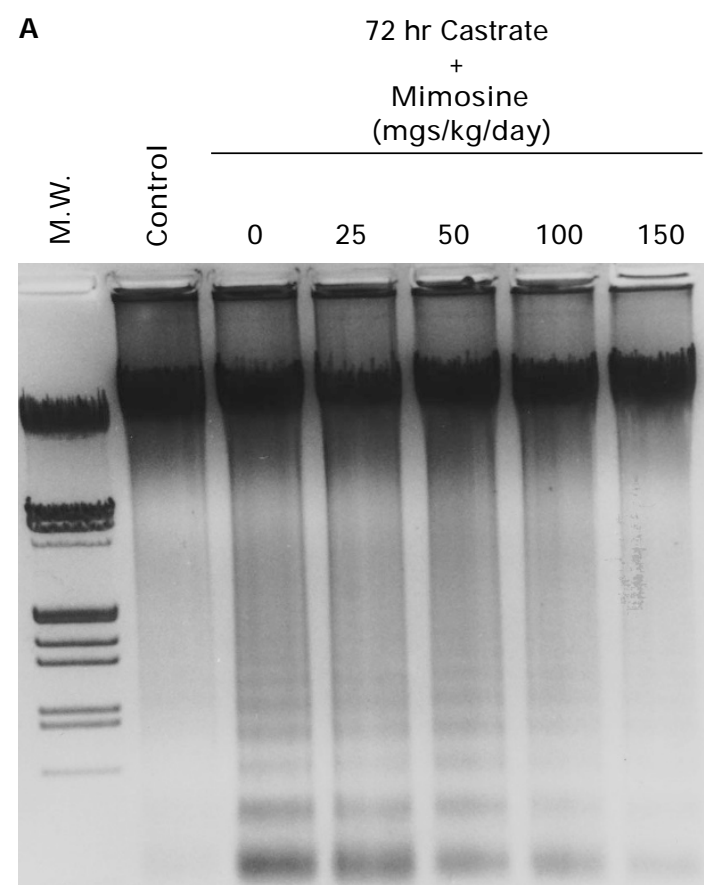

B

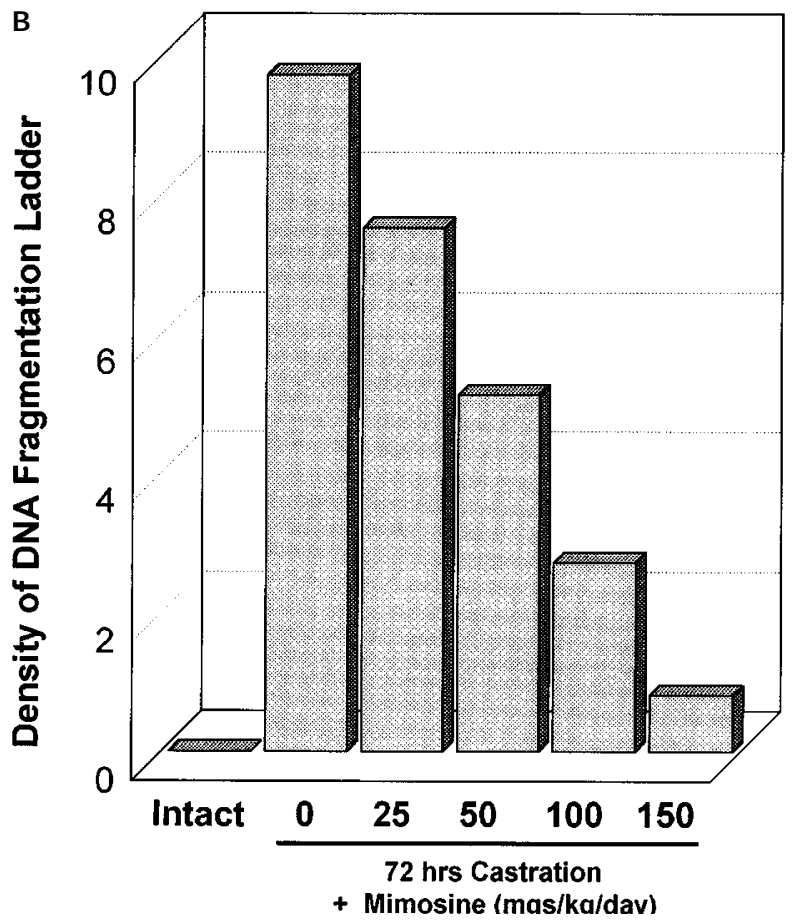

Figure 2 Dose-dependent suppression in apoptotic DNA fragmentation shows effect of increasing mimosine dose on regressing rat ventral prostate gland. (A) Electrophoretic analysis of DNAs extracted from rats at $72 \mathrm{~h}$ after castration with different doses of mimosine. Aliquots of DNAs (10 ugs) extracted from tissues, as indicated, were co-electrophesed on a $1.5 \%$ agarose gel. The gel was stained with ethidium bromide and photographed directly under ultraviolet light. Higher doses of mimosine increasingly suppressed the appearance of the DNA ladder at this single time point. (B) Graphical representation of the densitometric analysis of the second and third band (from the bottom) of the DNA ladder demonstrates dramatic suppression of DNA fragmentation in the regressing ventral prostate gland in a dose-dependent manner. By this means, it was estimated that DNA fragmentation was reduced by $90 \%$ at $72 \mathrm{~h}$ with a dose of mimosine treatment of $150 \mathrm{mg} / \mathrm{kg} / \mathrm{day}$ (i.p. injection). 
et al, 1993). This technique takes advantage of the ability of Klenow DNA polymerase to fill gaps in degraded nuclear DNA with digoxigenin-modified nucleotides. Labeled DNA in apoptotic cell nuclei can then be easily detected by an immunohistochemical staining procedure with monoclonal anti-digoxigenin antibody conjugated to alkaline phosphatase. We utilized this technique to stain sections of ventral prostate tissue obtained from untreated $60 \mathrm{~h}$ castrated rats or from mimosine-treated $60 \mathrm{~h}$ castrated rats $(150 \mathrm{mg} / \mathrm{kg} /$ day, i.p.). Following the immunohistochemical stain, the sections were counterstained with fast-green. Microscopic analysis of these tissues showed that the fast-green counterstain was sufficient to identify the presence of overt apoptotic bodies in both untreated and mimosinetreated regressing prostate tissues (Figure 4). These were recognized by their shrunken appearance and by their distinct separation from neighboring epithelial cells. However, remarkably, the nuclei of the apoptotic bodies in mimosine-treated specimens were refractory to staining by the ISGL technique (Figure 4), suggesting that the apoptotic process was ongoing in this tissue in the absence of the extensive nuclear DNA fragmentation usually associated with androgen-regulated prostate cell apoptosis. The results of this in situ detection method supports our DNA analytical experiments in showing that mimosine treatment suppressed the DNA fragmentation associated with prostate regression. However, based on our ability to identify apoptotic bodies by simple histochemical staining methods and to detected apoptosis-induced gene activity in mimosine-treated regressing prostate glands, the suppression of DNA fragmentation was not sufficient to inhibit the actual occurrence of apoptosis in the prostate gland.

Previously, a similar cell cycle blocking agent, hydroxyurea was tested for its effects on rat prostate cell apoptosis (Berges et al, 1993). The action of hydroxyurea is believed to be due to its inhibitory action against ribonucleotide reductase and a subsequent depletion of the intracellular deoxynucleotide triphosphate pool (Gilbert et al, 1995). Based on its mode of action, hydroxyurea likely allows complete transition through the $\mathrm{G}_{1}$ phase, but S-phase (as defined by DNA synthesis) cannot begin. Simple analysis of cell loss from the prostate gland after castration showed no difference between hydroxyureatreated and -untreated rats and it was concluded that cell cycle movement was not relevant for apoptosis in this situation (Berges et al, 1993). Here, we tested another cell cycle blocking drug, mimosine, that likely acts in a similar manner to hydroxyurea in suppressing cell cycle movement at the S-phase. Some of the most recent biochemical characterization of this substance suggests that it, like hydroxyurea, blocks the formation of replication forks of DNA in dividing cells (Gilbert et al, 1995), most likely by inhibiting deoxyribonucleotide metabolism. Indeed, mimosine has already proven to be an apoptosis-blocking drug when tested against NGF depleted PC12 cells (Farinelli and Green, 1996). In this situation, coordinate studies with drugs other than mimosine seem to confirm that $G_{1} \rightarrow S$ phase movement is important for certain neuronal cell deaths.

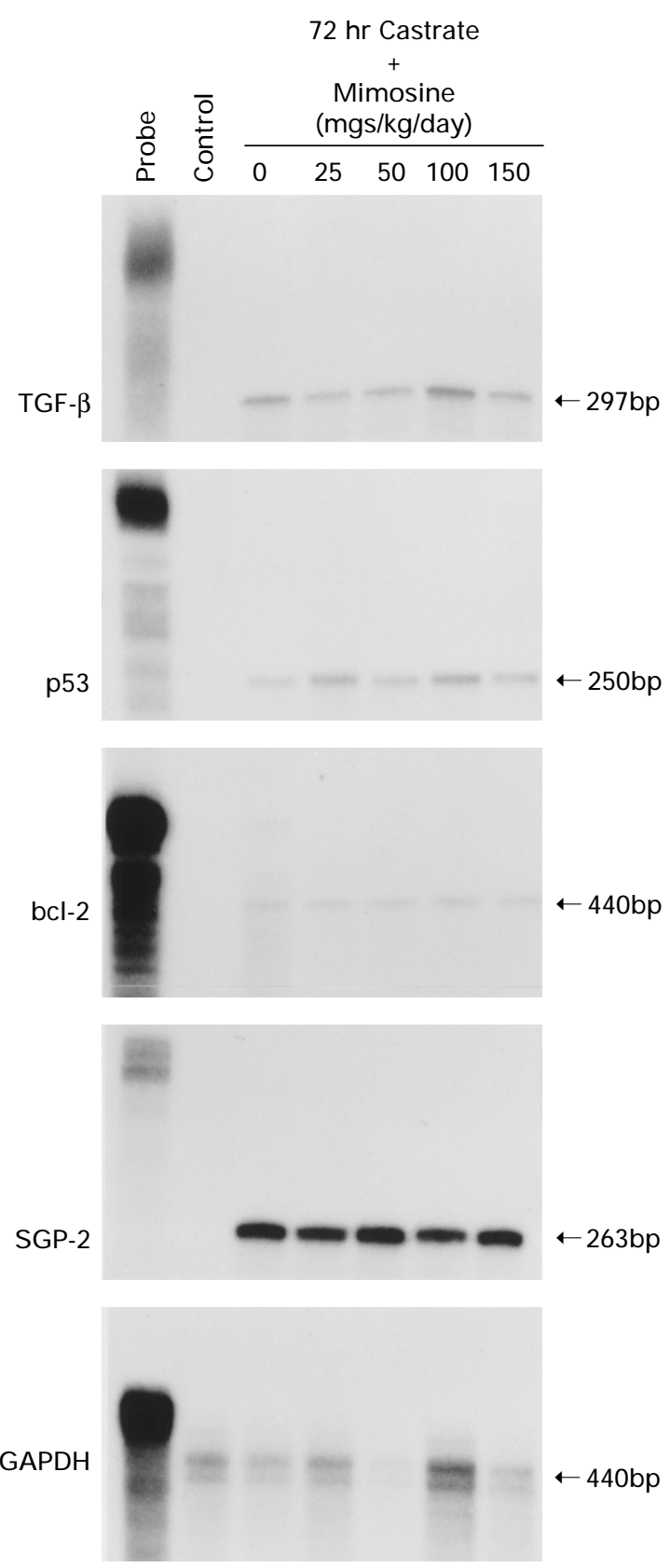

Figure 3 RNase protection analysis showed that the induction of prostatic castration-associated mRNA expression, including mRNAs encoding bcl-2, p53, SGP-2 and TGF- $\beta 1$, was not significantly affected by mimosine treatment, event at high doses (i.p. administration).

In our experiments, mimosine treatment of rats did not apparently suppress or alter the rate of androgen-withdrawal based apoptosis of prostate epithelial cells. These results are similar to those reported for hydroxyurea treatment of castrated rats, a drug which may act in a similar mechanism to mimosine in suppressing cell cycle movement at the early $S$ phase. Likewise, mimosine did not suppress the induced expression of certain gene products in the castrated rat prostate, many of which are important for the movement of cells through the $G_{1}$ phase of the cell 

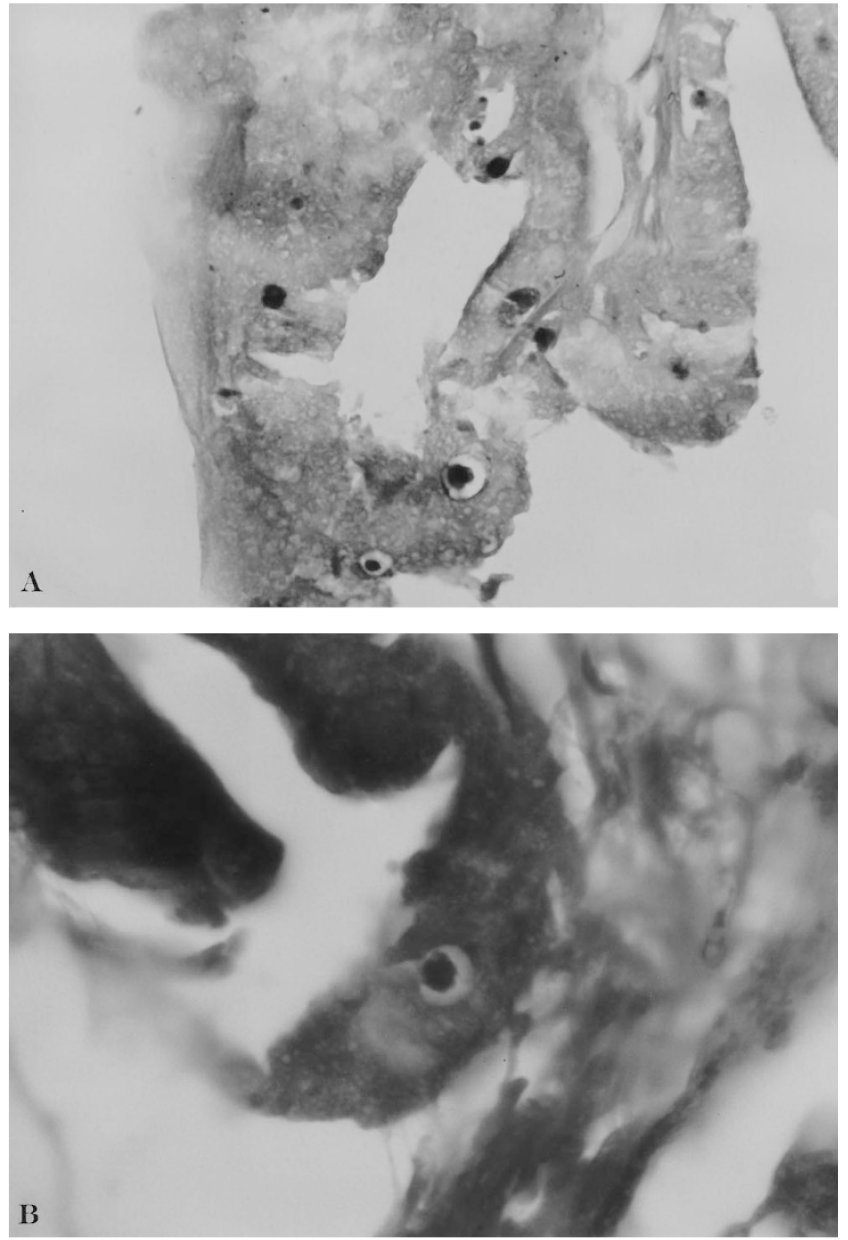

Figure 4 In situ-gap labeling (ISGL) method used ot detect fragmented DNA in apoptotic cells of the regressing rat ventral prostate gland fails to identify apoptotic bodies in mimosine-treated rats. (A) Thin sections of ventral prostates obtained from rats at $60 \mathrm{~h}$ after castration were stained using the ISGL enzymatic-immunohistochemical labeling technique with an alkalinephosphatase detection system. Nuclei of apoptotic bodies (arrows) are darkly stained by this technique. Tissue is counterstained with fast green. (B) Thin sections of ventral prostates obtained from rats at $60 \mathrm{~h}$ after castration with mimosine treatment $(150 \mathrm{mg} /$ day) were refractory to ISGL staining. Apoptotic bodies could be detected in these tissues with the fast green counter stain (arrows), but their nuclei were not labeled by this technique.

cycle. Given that neither of these drugs prevent movement of the cell cycle through the late $G_{1}$ phase to the S-phase, their failure to block androgen-regulated apoptosis in the rat prostate gland is not sufficient evidence that early cell cycle movement is not involved in the mechanism of these cell deaths. It is still possible that some events associated with the mid-to-late $G_{1}$ phase transition of the cell cycle are critical for the actual cell death mechanism involved in the prostate cells' response to androgen deprivation. It should be noted that mimosine did, however, strikingly affect some characteristics of apoptosis in these prostate cells, potently suppressing the appearance of nuclear DNA fragmentation. This may indicate that some aspect of replicative DNA synthesis, previously described in association with prostate regression (Colombel et al, 1992) is involved in the internucleosomal DNA fragmentation that accompanies prostate cell apoptosis. It will be interesting in the future to determine whether hydroxyurea treatment suppresses DNA fragmentation in this model system of apoptosis or whether this is a specific effect of mimosine. Likewise, it is likely to require novel agents that suppress cell cycle movement through the late $G_{1}$ phase to ultimately test this hypothesis.

\section{Materials and Methods}

\section{Animals and tissues}

Mature male Sprague-Dawley rats $(325-350 \mathrm{~g})$ were purchased from Camm, INN (Camden, New Jersey) and maintained with food and water ad libitum as recommended by the National Institute of Health Guidelines for the Care and Use of Laboratory Animals. Rats were surgically castrated as previously described (Zhang et al, 1994). Mimosine (Sigma, St Louis, MO) was administered by two methods, as indicated. Oral dosing was achieved by measuring the daily water intake of rats over the period of a week and then adding the drug to the water so that the expected daily intake would be $25 \mathrm{mg} / \mathrm{kg} / \mathrm{day}$. Alternatively, rats were injected, i.p. at daily intervals with an aqueous solution of mimosine to deliver the described dosage. Rats were sacrificed at the indicated times by a overdose of sodium pentobarbital, i.p., and the ventral prostate glands were removed. These tissues were flash-frozen in liquid nitrogen and stored in $-80^{\circ} \mathrm{C}$ for subsequent processing.

\section{Detection of ventral prostate gland DNA fragmentation}

Frozen ventral prostate tissues from treated/untreated castrated rats were pulverized under liquid nitrogen. DNA was extracted from $50 \mathrm{mg}$ frozen tissue powder using the ASAP genomic DNA extraction kit (Boehringer Mannheim Biochemicals, Indianapolis, IN) as previously described (Colombel et al, 1992) and was quantitated by spectrophotometer at $260 \mathrm{~nm}$. Aliquots containing $10 \mu \mathrm{g}$ of genomic DNA from each specimen were then electrophoresed on a $1.5 \%$ agarose gel. The gel was photographed under ultraviolet light subsequent to staining with ethidium bromide. The film negative obtained from these photos was analyzed by densitometry (Molecular Dynamics Scanning Densitometer) for the relative density of the second and third bands from the bottom of the DNA ladder to quantitatively compare the amount of DNA fragmentation between mimosine-treated and untreated specimens.

\section{RNA extraction and analysis}

Frozen rat ventral prostate tissues were pulverized under liquid nitrogen and then the total RNA was extracted with the use of the RNAzole B regent (TelTest, Inc, Friendswood, TX) as previously described (Zhang et al, 1994). Small cDNA fragments for bcl-2 were obtained by PCR amplification of oligo-dT primed, reverse transcribed RNA from rat ventral prostate gland using PCR primers designed by a software analysis program, Oligo 4.0 (National Biosciences, Hameln, $\mathrm{MN}$ ), applied to the known sequence of human bcl-2 in Genebank (Tsujimoto and Croce, 1986). The PCR primers for rat TGF- $\beta 1$ were purchased from Clonetech, Inc (Palo Alto, CA). Amplified DNA fragments were cloned into the TA II cloning vector (Invitrogen, San Diego, CA) and sequenced using standard didoxunucleotide methods. Riboprobe expression vectors for rat p53, SGP-2 and GAPDH were previously described (Zhang et al, 1994). Ribonuclease protection 
assay was performed as described (Zhang et al, 1994) using RPA II ribonuclease protection assay kit from Ambion, Inc (Austin, TX). Briefly, riboprobes were synthesized from plasmid by T7 or SP6 RNA polymerase using $\left.{ }^{32} \mathrm{P}\right]$-UTP and aliquots containing $2 \times 10^{5} \mathrm{cpm}$ antisense gel purified riboprobes were hybridized with $20 \mu \mathrm{g}$ aliquots of total RNA extracted from control and experimental rat ventral prostate glands overnight at $45^{\circ} \mathrm{C}$ and followed by RNase treatment for $30 \mathrm{~min}$ at $37^{\circ} \mathrm{C}$. Digests were applied to $8 \%$ acrylamide sequencing gels and then was exposed to X-ray film to produce an autoradiography. Densitometry was performed on films, when indicated, with the Molecular Dynamics Scanning Laser Densitometer.

\section{In situ-gap labeling (ISGL) of fragmented DNA and histologic identification of apoptotic bodies}

Regressing ventral prostate glands (60h after castration) from mimosine-treated and-untreated rats were fixed in $4 \%$ paraformaldehyde in phosphate-buffered saline overnight, then soaked in $25 \%$ sucrose, phophate-buffered saline for 12 to $24 \mathrm{~h}$. The tissues were dehyrated and embedded in paraffin blocks using standard conditions. Thin sections $(5 \mu \mathrm{m})$ were cut from the blocks and stained by the In Situ-Gap Labeling procedure as previously described (Santarosa et al, 1994). Briefly, rehydrated tissues were digested in $0.1 \mathrm{M}$ sodium acetate, $\mathrm{pH} 2.0$ containing $0.1 \%$ pepsin for $30 \mathrm{~min}$ at $37^{\circ} \mathrm{C}$. Slides were washed and incubated with $50 \mathrm{mM}$ Tris- $\mathrm{HCl}(\mathrm{pH} 7.5), 5 \mathrm{mM}$ $\mathrm{MgCl}_{2}, 10 \mathrm{mM}$ 2-mercaptoethanol, and $0.005 \%$ bovine serum albumin containing $1 \mathrm{mM}$ dATP, dTTP, dGTP, $100 \mathrm{mM}$ digoxigenin-labeled dUTP and 100 units $/ \mathrm{ml}$ of Klenow DNA polymerase (Boehringer Mannheim Biochemicals, Indianapolis, IN) at $15^{\circ} \mathrm{C}$ for $30 \mathrm{~min}$. The slides were then washed in $0.1 \mathrm{M}$ sodium maleate and treated with a blocking solution from Boehringer Mannheim, Inc. (Indianapolis, IN), then incubated with alkaline phosphatase-conjugated monoclonal mouse anti-digoxigenin antibody from Boehringer Mannheim, Inc. (Indianapolis, IN) for $45 \mathrm{~min}$ at $37^{\circ} \mathrm{C}$. Alkaline phosphatase activity was detected with substrates 5 -bromo-4-chloro-3-indolylphosphate $\rho$ toluidine, and nitroblue tetrazolium chloride (NBT). Tissues were lightly counterstained with methylene green, dehydrated and mounted for photomicroscopy.

\section{Effect of mimosine on protein synthesis in the regressing prostate gland}

A group of six rats was castrated and subsequently treated with mimosine at $150 \mathrm{mg} /$ day (i.p. injection) for $48 \mathrm{~h}$. Control rats $(n=6)$ were castrated for $48 \mathrm{~h}$ but received no mimosine treatment. Control and treated rats then received a bolus of $0.5 \mathrm{mCi}\left[{ }^{35} \mathrm{~S}\right]$-methionine (Amersham Inc., Arlington Heights, IL) administered by i.v. injection into the femoral vein. Two hours later, all rats were sacrificed and ventral prostate tissue was recovered, weighed and pulverized to a fine powder under liquid nitrogen for subsequent extraction and quantitation of radiolabeled $\left[{ }^{35} \mathrm{~S}\right]$ content. The powder was homogenized in a buffer containing $25 \mathrm{mM}$ Tris- $\mathrm{HCl}(\mathrm{pH} 7.5), 1 \mathrm{mM}$ EDTA, and $0.5 \%$ Triton X-100 for 2 min with Polytron Homogenizer (Brinkmann Instruments, Inc., Westbury, NY). Aliquots of 250, 150 and $50 \mu \mathrm{ls}$ were precipitated in ice cold $5 \%$ TCA (Maniatis et al, 1982). The precipitate was collected by filtering the solution through a GF/C glassfiber filter in a Whatman vacuum filtration apparatus (Whatman International Ltd, Maidstone, England). Filters were washed five times with $5 \%$ TCA followed by $95 \%$ ethanol, air dried and then placed into vials with liquid scintillation fluid. $\left[{ }^{35} \mathrm{~S}\right]$ was counted in a LKB Wallac liquid scintillation counter. $\left[{ }^{35} \mathrm{~S}\right]$-methionine incorporation is reported as CPMs $\left[{ }^{35} \mathrm{~S}\right]$ in TCA insoluble material $/ \mathrm{mg}$ tissue.

\section{Acknowledgements}

This work was partially supported by grants from the NIH (CA47848) and from the Urology Research fund of the Columbia-Presbyterian Medical Center.

\section{References}

Berges RR, Furuya Y, Remington L, English HF, Jacks T and Isaacs JT (1993). Proliferation, DMA repair and p53 function are not required for programmed death of prostatic glandular cells induced by androgen ablation. Proc. Natl. Acad. Sci. USA. 90: 8910-8914

Buttyan R, ZakeriZ, Lockshin Rand Wolgemuth D (1988). Cascade induction of the cfos, c-myc and hsp-70k transcripts in the regressing rat ventral prostate gland. Mol. Endocrinol. 2: 650-657

Buttyan R, Olsson CA, Pintar J, Chang C, Bandyk M, Ng P-Y and Sawczuk IS (1989). Induction of the TRPM-2 gene in cells undergoing programmed death. Mol. Cell. Biol. 9: 3473-3481

Buttyan R (1991). Genetic response of prostate cells to androgen deprivation: Insights into the cellular mechanism of apoptosis. In: Apoptosis: The molecular basis of cell death. In: Tomei LD and Cope FO, (eds). (New York, Cold Spring Harbor Laboratory Press). pp 157-173

Colombel M, Olsson CA, Ng P-Y and Buttyan R (1992). Hormone-regulated apoptosis results from reentry of differentiated prostate cells onto a defective cell cycle. Cancer Res. 52: 4313-4319

Colombel M and Buttyan R (1995). Hormonal control of apoptosis: the rat prostate gland as model system. Methods In Cell Biol. 46: 369-385

Crounse RG, Maxwell JD and BlankH(1962). Inhibition of growth of hair by mimosine. Nature. 194: 694-695

Farinelli SE and Greene LA (1996). Cell cycle blockers mimosine, ciclopirox, and deferoxamine prevent the death of PC12 cells and postmitotic sympathetic neurons after removal of trophic support. J. Neuroscience. 16: 1150-1162

Gilbert DM, Neilson A, Miyazawa H, DePamphilis ML and Burhans WC (1995) Mimosine arrests DNA synthesis at replication forks by inhibiting deoxyribonucleotide metabolism. J. Bio. Chem. 270: 9597-9606

Kyprianou N and Isaacs JT (1988). Activation of programmed cell death in the rat ventral prostate after castration. Endocrinl. 122: 552-562

Kyprianou N and Isaacs JT. (1989) Expression of transforming growth factor- $\beta$ in the rat ventral prostate during castration-induced programmed cell death. Mol. Endocrinol. 3: 1515-1522

Lee $C$ (1981). Physiology of castration-induced regression in rat prostate. Prog. Clin. Bio. Res. 75A: $145-159$

McDonnell TJ, Troncoso P, Brisbay SM, Logothesis C, Chung LWK, Hsieh JT, Tu SM and Campbell ML (1992). Expression of the proto-oncogene bcl-2 in the prostate and its association with the emergence of androgen-independent prostate cancer. Cancer Res. 52: 6940-6944

Maniatis T, Fritsch DF and Sambrook J (1982). In: Molecular Cloning, (New York: Cold Spring Harbor Laboratory Press) pp. 473

Meyaard MJ, Otto SA, Jonker RR, Mijnster MJ, Keet RP and Miedema F (1992). Programmed death of T-cells in HIV-1 infection. Science 257: 217-219

Page MJ and Parker MG (1982). Effects of androgen on the transcription of rat prostatic binding genes. Mol. Cell. Endocrinol. 27: 343-355

Sanford ML, Searle JE and Kerr JFR (1984). Successive wave of apoptosis in the rat prostate after repeated withdrawal of testosterone stimulation. Pathology 16 : $406-410$

Santarosa R, Colombel M, Kaplan S, Monson F, Levin RM and Buttyan R (1994). Opposing Cellar Processes that regulate the response of the rabbit bladder to transient outlet obstruction. Lab. Invest. 70: 503-510

Thompson JF, Morris CJ and Smith IK (1969). New naturally occurring amino acids. Annu. Rev. Biochem. 38: 137-158

Tsujimoto $Y$ and Croce C (1986). Analysis of the structure, transcripts and protein product of bcl-2, the gene involved in human follicular lymphoma. Proc. Natl. Acad. Sci. USA 83: 5214-5219

Watson PA, Hanauske-Abel HH, Flint A and Lalande M (1991). Mimosine reversibly arrests cell cycle progression at the $G_{1}-S$ phase Border. Cysmetry. 12: 242-246 
Mimosine-suppressed DNA fragmentation in rat prostate cell apoptosis $X$ Zhang et al

Wijsman JH, Jonker RR, Kejzer R, Van DeVelde CJH, Cornelisse CJ and Van Dierendonck JK (1993). A new method to detect apoptosis in paraffin section: in situ end-labeling of fragmented DNA. J. Histochem. Cytochem. 41: 7-12
Zhang X, Colombel M, Raffo A and Buttyan R (1994). Enhanced expression of p53 mRNA and protein in regressing rat ventral prostate gland. Biochem. Bioph. Res. Comm. 198: 1189-1194 